\title{
EDITORIAL
}

\section{Yu-Chi HO}

\section{Foreword to a special issue on networks}

\author{
(c) Higher Education Press and Springer-Verlag Berlin Heidelberg 2011
}

If the decade of 1990s were the period of Globalization, the first ten years of this new century can certainly be characterized as the age of Connectedness. Through "connectedness" the world becomes Friedmanianly flat, people are enabled, informed, and equipped to deal with a complex, hot, and crowded world. Not only there is the ubiquitous Internet from which all of us are increasingly dependent, but there are many other kinds of networks, social, commercial, economic, and military that drive our civilization.

Researches on network correspondingly begin to take off. By hindsight it was prescient on the part of Tsinghua University to establish in 2001 the Center for Intelligent and Networked Systems (CFINS) as a new venture both in administrative structure and research direction in an academic environment. The choice of a home for CFINS in the Department of Automation is also strategic in the sense of broadest inclusion. CFINS' research effort is not a subset of computer science, electrical engineering, communication, or operations and system research. But rather it is all encompassing and cross disciplinary. The experience of the past nine years vindicated these decisions.

Here in this special issue, we have a sampling of technical contribution and research interest from personnel of CFINS, the oversea as well as resident faculties and visiting members.

For more information on CFINS please go to the CFINS website http://www.cfins.au.tsinghua.edu.cn/en/about/ index.php as well as http://sciencenet.cn/m/user_content.aspx?id=8897.

\section{Yu-Chi HO}

Center for Intelligent and Networked Systems

Tsinghua University

Member of NAE, CAS, CAE

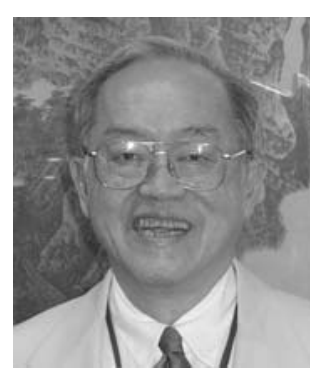

Yu-Chi (Larry) HO received his undergraduate and graduate education from MIT and Harvard University respectively. For over forty years he taught and did research on the Harvard faculty. He is active professionally in numerous capacities as editor of journals, author of books and paper classics, and received numerous awards. He is a life fellow of IEEE, elected member of the U.S. National Academy of Engineering and an elected foreign member of the Chinese Academy of Sciences and the Chinese Academy of Engineering. Since October 2001, he also acts part time as the chief scientist and chaired professor of the Center for Intelligent and Networked Systems at Tsinghua University, Beijing, China, and since 2007 a regular popular blogger on ScienceNet China. 